\title{
Stroke subtype, vascular risk factors, and total MRI brain small-vessel disease burden OPEN
}

Julie Staals, MD, PhD

Stephen D.J. Makin, MBChB

Fergus N. Doubal, MBChB, PhD

Martin S. Dennis, MBChB, MD, FRCP Joanna M. Wardlaw, MBChB, MD, FRCR

Correspondence to Dr. Wardlaw: joanna.wardlaw@ed.ac.uk

Editorial, page 1224

Supplemental data at Neurology.org

\section{ABSTRACT}

Objectives: In this cross-sectional study, we tested the construct validity of a "total SVD score," which combines individual MRI features of small-vessel disease (SVD) in one measure, by testing associations with vascular risk factors and stroke subtype.

Methods: We analyzed data from patients with lacunar or nondisabling cortical stroke from 2 prospective stroke studies. Brain MRI was rated for the presence of lacunes, white matter hyperintensities, cerebral microbleeds, and perivascular spaces independently. The presence of each SVD feature was summed in an ordinal "SVD score" (range 0-4). We tested associations with vascular risk factors, stroke subtype, and cerebral atrophy using ordinal regression analysis.

Results: In 461 patients, multivariable analysis found that age (odds ratio [OR] 1.10, 95\% confidence interval [Cl] 1.08-1.12), male sex (OR 1.58, 95\% Cl 1.10-2.29), hypertension (OR 1.50, $95 \% \mathrm{Cl} 1.02-2.20)$, smoking (OR 2.81, 95\% Cl 1.59-3.63), and lacunar stroke subtype (OR $2.45,95 \% \mathrm{Cl} 1.70-3.54)$ were significantly and independently associated with the total SVD score. The score was not associated with cerebral atrophy.

Conclusions: The total SVD score may provide a more complete estimate of the full impact of SVD on the brain, in a simple and pragmatic way. It could have potential for patient or risk stratification or early efficacy assessment in clinical trials of interventions to prevent SVD progression and may (after further testing) have a useful role in clinical practice. Neurology ${ }^{\circledR}$ 2014;83:1228-1234

\section{GLOSSARY}

$\mathbf{A F}=$ atrial fibrillation; $\mathbf{C l}=$ confidence interval; $\mathbf{C M B}=$ cerebral microbleed; $\mathbf{D W I}=$ diffusion-weighted imaging; $\mathbf{F L A I R}=$ fluid-attenuated inversion recovery; $\mathbf{O R}=$ odds ratio; PVS = perivascular space; $\mathbf{S V D}=$ small-vessel disease; $\mathbf{W M H}=$ white matter hyperintensity.

Cerebral small-vessel disease (SVD) is an intrinsic disorder of the small perforating arterioles. ${ }^{1}$ SVD is a common cause of dementia and stroke, and causes considerable worsening of cognitive function, gait, and balance. ${ }^{2}$

On brain MRI, 4 closely correlated features are markers of SVD: lacunes, white matter hyperintensities (WMH), cerebral microbleeds (CMBs), and visible perivascular spaces (PVS). ${ }^{1,2}$ Cerebral atrophy may also be associated with SVD. ${ }^{3-5}$ These individual SVD features are each associated with vascular risk factors. ${ }^{6-9}$ Few studies have combined these features to capture the "total SVD burden" or tested for associations with stroke subtype or vascular risk factors. ${ }^{10,11} \mathrm{~A}$ total SVD burden score might capture the overall effect of SVD on the brain better than by considering only 1 or 2 individual features separately. For example, WMH usually occur in white matter whereas lacunes usually occur in deep gray matter; one score including both features would reflect total brain damage better.

Recently, our Maastricht collaborative group ${ }^{12}$ developed a pragmatic estimate of total SVD burden in patients with lacunar stroke by summing the different MRI features that were present, yielding a 0 to 4 "total SVD score." This total SVD score was associated with blood pressure ${ }^{12}$

From the Centre for Clinical Brain Sciences (S.D.J.M., F.N.D., M.S.D., J.M.W.), University of Edinburgh, UK; and Department of Neurology and Cardiovascular Research Institute Maastricht (J.S.), Maastricht University Medical Centre, the Netherlands.

Go to Neurology.org for full disclosures. Funding information and disclosures deemed relevant by the authors, if any, are provided at the end of the article. The Article Processing Charge was paid by funding provided by the Wellcome Trust to the University of Edinburgh for open access charges. This is an open access article distributed under the Creative Commons Attribution License, which permits unrestricted use, distribution, and reproduction in any medium, provided the original work is properly cited. 
and $\operatorname{cognition}^{13}$ in patients with lacunar stroke. This pragmatic estimate of total SVD burden could be useful for rapid quantification or stratification of SVD, e.g., in clinical trials, ${ }^{2}$ genetic studies, ${ }^{10,11}$ and potentially in clinical practice. Before wider use, further testing of the score's generalizability in larger, more varied cohorts is required.

We investigated whether the SVD score is a valid representation of SVD by testing whether previously described risk factors for individual SVD features were associated with total SVD score, whether SVD score was higher in patients presenting with recent lacunar stroke compared with cortical stroke, and any association with cerebral atrophy.

METHODS We report our results according to the Standards for Reporting Vascular Changes on Neuroimaging (STRIVE) for reporting studies in SVD (www.equatornetwork.org). ${ }^{14}$ For clarity, we refer to the clinical stroke syndrome as "lacunar stroke," the new acute small subcortical infarct seen on MRI as the recent small subcortical (or lacunar) infarct, and the small cavities that represent old lacunar infarcts as lacunes. ${ }^{14}$

Patients. We used data from 2 nonoverlapping studies of patients recruited prospectively and consecutively with lacunar or mild cortical ischemic stroke (study 1, 2003-2007; study 2, 2010-2012, publication pending), which used very similar methods, described previously. ${ }^{7}$ These studies recruited patients with a definite diagnosis of clinical lacunar or mild cortical ischemic stroke who presented to the hospital stroke service (Western General Hospital, Edinburgh, UK) within 3 months of onset; patients with MRI contraindications, unstable medical condition, previous stroke, and severe (i.e., disabling) stroke were excluded.

Vascular risk factors. In the primary studies, experienced physicians qualified in stroke medicine recorded baseline demographics, vascular risk factors, and other details. Hypertension (blood pressure $\geq 140 / 90 \mathrm{~mm} \mathrm{Hg}$ ), diabetes mellitus (fasting blood glucose $\geq 6.1 \mathrm{mmol} / \mathrm{L}$ ), hypercholesterolemia (total cholesterol $>5.0$ $\mathrm{mmol} / \mathrm{L}$ ), ischemic heart disease (myocardial infarction, angina, or ECG evidence of myocardial ischemia), and peripheral vascular disease (symptoms of intermittent claudication) were defined as previously diagnosed by a physician/general practitioner, on current treatment, or newly diagnosed at stroke presentation. Symptomatic carotid stenosis was defined as stenosis $\geq 50 \%$ NASCET (North American Symptomatic Carotid Endarterectomy Trial criteria) in the symptomatic artery, atrial fibrillation (AF) as either previous diagnosis or AF seen on ECG, and smoking as current smoking.

Brain MRI acquisition. Patients had brain MRI on the day of presentation (median 7; interquartile range 15 days after stroke) on a research-dedicated 1.5T MR scanner (Signa LX; General Electric, Milwaukee, WI) operated by research-dedicated technical staff and which underwent daily quality assurance monitoring. Sequences included axial diffusion-weighted imaging (DWI), T2-weighted, fluid-attenuated inversion recovery (FLAIR), gradient echo, and sagittal T1-weighted sequences (for details see table e-1 on the Neurology ${ }^{\circledR}$ Web site at Neurology.org).
Stroke subtype classification. Strokes were initially classified into clinical lacunar or cortical stroke syndromes according to the Oxfordshire Community Stroke Project classification. ${ }^{15}$ Final lacunar or cortical stroke diagnosis was based on both clinical and radiologic findings after review of all clinical and investigative information by a panel of stroke clinical and imaging experts, an established methodology for stroke subtype classification in research. ${ }^{16}$ If clinical and radiologic classifications differed, ${ }^{17}$ the radiologic classification was used. If no definite recent ischemic lesion corresponding with the presenting symptoms was visible on MRI, the clinical classification was used.

Standard protocol approvals, registrations, and patient consents. Both studies were approved by the local research ethics committee and all participants gave written informed consent.

MRI analysis. All MRIs were assessed blinded to clinical information by one experienced neuroradiologist for the presence, location, and size of the recent symptomatic infarct and any other vascular lesions. A recent infarct was defined as a hyperintense area on DWI with corresponding reduced signal on the apparent diffusion coefficient image, with or without increased signal on FLAIR or T2-weighted imaging, that corresponded with a typical vascular territory. ${ }^{18}$ Recent small subcortical (lacunar) infarcts were defined as rounded or ovoid lesions with signal characteristics as above, $>3$ - but $<20$-mm diameter, in the basal ganglia, internal capsule, centrum semiovale, or brainstem and carefully distinguished from WMH. ${ }^{1}$ Cortical infarcts were defined as infarcts involving cortical \pm adjacent subcortical tissue, or large $(>2-\mathrm{cm}) \quad$ striatocapsular/subcortical lesions. ${ }^{14}$ Lacunes were defined as rounded or ovoid lesions, $>3$ - and $<20-\mathrm{mm}$ diameter, in the basal ganglia, internal capsule, centrum semiovale, or brainstem, of CSF signal intensity on T2 and FLAIR, generally with a hyperintense rim on FLAIR and no increased signal on DWI. ${ }^{14}$ Microbleeds were defined as small $(<5 \mathrm{~mm})$, homogeneous, round foci of low signal intensity on gradient echo images in cerebellum, brainstem, basal ganglia, white matter, or cortico-subcortical junction, differentiated from vessel flow voids and mineral depositions in the globi pallidi. ${ }^{14}$ Deep and periventricular WMH were both coded according to the Fazekas scale from 0 to $3 .{ }^{19}$ We defined PVS as small $(<3$ $\mathrm{mm})$ punctate (if perpendicular) and linear (if longitudinal to the plane of scan) hyperintensities on T2 images in the basal ganglia or centrum semiovale, and they were rated on a previously described, validated semiquantitative scale from 0 to $4 .{ }^{7}$ Cerebral atrophy was classified for both deep (enlargement of the ventricles) and superficial (enlargement of the sulci) components on a 4-point scale (absent, mild, moderate, severe) in study 1, and on a modified 6-point version of the same scale in study $2 .{ }^{20}$ The atrophy grade is determined by comparison with templates indicating normal to atrophied brains obtained in research into normal subjects on our scanner. ${ }^{20}$ To merge the data from both studies, we condensed study 2's version to 4 categories (1 absent, 23 mild, 4 moderate, 5-6 severe). The intraclass correlation coefficient for WMH intraobserver rating (100 scans) was 0.96 . The intrarater $\kappa$ for PVS ( 50 scans) was 0.80 to 0.90 (unpublished data), for lacunes was 0.85 (unpublished data), and for microbleeds was 0.68 to $0.78 .{ }^{21}$

Determining the total MRI burden of SVD. Based on the recently described score, ${ }^{12}$ we rated the total MRI burden of SVD on an ordinal scale from 0 to 4 , by counting the presence of each of the 4 MRI features of SVD. A point was awarded for each of the following (figure): presence of lacunes and CMBs were defined as the presence of one or more lacunes (1 point if present) or any CMB (1 point if present). Presence of PVS was 


\begin{tabular}{|c|c|c|c|c|}
\hline MRI feature & $\begin{array}{c}\text { Visual } \\
\text { assessment }\end{array}$ & Definition & Score & MRI example \\
\hline Lacunes & $\begin{array}{l}\text { International } \\
\text { consensus } \\
\text { definition }^{14}\end{array}$ & $\geq 1$ Lacune & $\begin{array}{l}1 \\
\text { point }\end{array}$ & \\
\hline Microbleeds & $\begin{array}{l}\text { International } \\
\text { consensus } \\
\text { definition }^{14}\end{array}$ & $\geq 1$ Microbleed & $\begin{array}{l}1 \\
\text { point }\end{array}$ & \\
\hline $\begin{array}{l}\text { Perivascular } \\
\text { spaces }\end{array}$ & $\begin{array}{l}\text { Semiquantitative } \\
\text { scale }^{7}\end{array}$ & $\begin{array}{l}\text { Moderate to severe } \\
\text { perivascular } \\
\text { spaces in basal } \\
\text { ganglia }\end{array}$ & $\begin{array}{l}1 \\
\text { point }\end{array}$ & \\
\hline $\begin{array}{l}\text { White matter } \\
\text { hyperintensities } \\
(\text { WMH) }\end{array}$ & Fazekas scale ${ }^{19}$ & $\begin{array}{l}\text { Periventricular } \\
\text { WMH Fazekas } 3 \\
\text { (extending into the } \\
\text { deep white matter) } \\
\text { and/or deep WMH } \\
\text { Fazekas 2-3 } \\
\text { (confluent or early } \\
\text { confluent) }\end{array}$ & $\begin{array}{l}1 \\
\text { point }\end{array}$ & \\
\hline
\end{tabular}

counted if there were moderate to severe (grade 2-4) PVS in the basal ganglia (1 point if present). Presence of WMH was defined as either (early) confluent deep WMH (Fazekas score 2 or 3) or irregular periventricular WMH extending into the deep white matter (Fazekas score 3) (1 point if present).

Because WMH are the most frequently described SVD feature in the literature, ${ }^{14}$ we tested the effect of different cutpoints in the WMH score by lowering the cutoff of deep WMH to Fazekas score 1, 2, or 3 (punctate or [early] confluent areas), and of periventricular WMH to Fazekas score 2 or 3 (halo or extending into the deep white matter). We then calculated 2 alternative total SVD scores with these lowered deep or lowered periventricular WMH definitions.

Statistical analysis. We used $\chi^{2}$ test and Mann-Whitney test to test for differences between lacunar and cortical stroke. We performed univariable ordinal regression analysis with SVD score as dependent variable to investigate the association with vascular risk factors and stroke subtype. We then performed multivariable ordinal regression analysis with age, sex, stroke subtype, risk factors that are frequently associated with individual features of SVD, i.e., hypertension, diabetes mellitus, and smoking, and any other factor that was found to be associated in the univariable analysis at $p<0.05$. We explored the association between deep and superficial atrophy and SVD score by univariable and multivariable ordinal regression analysis with correction for age and sex and additionally for stroke subtype, hypertension, diabetes mellitus, and smoking. Finally, we tested the effect of the different cutoffs in the WMH score (specified above) by performing a logistic regression analysis with stroke subtype as dependent variable and SVD score as predictor variable, successively using the original SVD score and alternative SVD scores with lowered cutoff points in WMH definition. Results are presented as odds ratio (OR) with $95 \%$ confidence interval (CI). All analyses were performed with SPSS statistics version 20 (IBM Corp., Armonk, NY).

RESULTS Of 466 patients in the original studies, 5 were excluded because of missing MRI data, leaving 461 patients for inclusion-222 patients $(48 \%)$ with lacunar stroke and 239 (52\%) with cortical stroke. We identified a symptomatic stroke lesion on MRI in 341 patients (74\%): based on DWIhyperintensity in 314 patients $(68 \%)$ and on other sequences in 27 (6\%); in 264 of these (77\%), MRI classification matched clinical classification. In 120 patients (26\%), the stroke subtype was based on clinical findings only. Median age was 68.1 (33.896.9) years; other characteristics are summarized in table 1. Patients with lacunar stroke were younger with lower rates of $\mathrm{AF}$ and symptomatic carotid 
Table 1 Clinical and radiologic characteristics of the study population

\begin{tabular}{|c|c|c|c|}
\hline & All patients $(n=461)$ & Lacunar stroke $(n=222)$ & Cortical stroke $(n=239)$ \\
\hline Age, y & $68.1(33.8-96.9)$ & $66.3(34.7-96.9)$ & $69.7(33.8-92.1)^{a}$ \\
\hline Male sex & $286(62)$ & $130(59)$ & $156(65)$ \\
\hline Ischemic heart disease & $90(20)$ & $35(16)$ & $55(23)$ \\
\hline Peripheral vascular disease & $22(5)$ & $8(4)$ & $14(6)$ \\
\hline Diabetes mellitus & $59(13)$ & $32(14)$ & $27(11)$ \\
\hline Hypertension & $300(65)$ & $137(62)$ & $163(68)$ \\
\hline Smoking ${ }^{b}$ & 148 (33) & $80(37)$ & $68(29)$ \\
\hline Hypercholesterolemia $^{\mathrm{b}}$ & $210(46)$ & $96(44)$ & $114(48)$ \\
\hline Symptomatic carotid stenosis $\geq 50 \%{ }^{b}$ & $41(9)$ & $9(4)$ & $32(14)^{a}$ \\
\hline Atrial fibrillation & $50(11)$ & $15(7)$ & $35(15)^{a}$ \\
\hline Family history of stroke ${ }^{b}$ & $113(25)$ & $56(26)$ & $57(24)$ \\
\hline \multicolumn{4}{|l|}{ MRI features } \\
\hline Lacunes & $94(20)$ & $63(28)$ & $31(13)^{a}$ \\
\hline WMH & $170(37)$ & $84(38)$ & $86(36)$ \\
\hline CMBs & $71(15)$ & $40(18)$ & $31(13)$ \\
\hline PVS & $209(45)$ & $116(52)$ & $93(39)^{a}$ \\
\hline \multicolumn{4}{|l|}{ Cerebral atrophy } \\
\hline Deep atrophy & $1(0-3)$ & $1(0-3)$ & $1(0-3)$ \\
\hline Superficial atrophy & $1(0-3)$ & $1(0-3)$ & $1(0-3)$ \\
\hline
\end{tabular}

Abbreviations: $\mathrm{CMB}=$ cerebral microbleed; PVS = perivascular spaces; $\mathrm{WMH}=$ white matter hyperintensities.

Data presented as number (\%) or median (range).

${ }^{a} p<0.05$ cortical vs lacunar stroke.

${ }^{b}$ Nine missing in smoking; 2 missing in hypercholesterolemia; 27 missing in symptomatic carotid stenosis; 13 missing in family history of stroke.

stenosis than those with cortical stroke. Of the 4 MRI features, WMH and PVS were most prevalent; lacunar stroke patients more often had lacunes and PVS (table 1).

Total SVD score. Of the patients who scored 1, most (45\%) had PVS, followed by WMH (29\%), lacunes (15\%), and CMBs (11\%) (table 2). Of those who scored 2, all combinations were present, but the combination of PVS and WMH was predominant (64\%). Of those who scored 3, all potential combinations were present, but PVS + WMH + lacunes $(43 \%)$ and PVS + WMH + CMBs (44\%) were most prevalent. Lacunar stroke patients had higher ratings of

\begin{tabular}{|llll|}
\hline Table 2 & \multicolumn{2}{l|}{ Total SVD score values for all patients and by stroke subtype } \\
\hline SVD score & All patients ( $\mathbf{N}=461)$ & Lacunar stroke $(\mathbf{n}=222)$ & Cortical stroke $(\mathbf{n}=239)$ \\
0 & $181(39)$ & $73(33)$ & $108(45)$ \\
1 & $112(24)$ & $53(24)$ & $59(25)$ \\
2 & $88(19)$ & $48(22)$ & $40(17)$ \\
3 & $64(14)$ & $38(17)$ & $26(11)$ \\
4 & $16(4)$ & $10(4)$ & $6(2)$
\end{tabular}

Abbreviation: SVD = small-vessel disease.

Data presented as number (\%). Mann-Whitney test lacunar vs cortical stroke, $p=0.001$.
SVD burden compared with cortical stroke patients (table 2; $p=0.001$ ).

Association with vascular risk factors and stroke subtype. In univariable analysis, total SVD score was significantly associated with age (OR 1.07, 95\% CI 1.061.09 per year), male sex (OR 1.44, 95\% CI 1.022.03), peripheral vascular disease (OR $2.46,95 \% \mathrm{CI}$ 1.15-5.30), hypertension (OR 1.82, 95\% CI 1.282.60), and lacunar stroke subtype (OR $1.73,95 \%$ CI 1.24-2.41), but not with diabetes, smoking, hypercholesterolemia, ischemic heart disease, AF, symptomatic carotid stenosis, or family history of stroke.

On multivariable analysis (table 3), age (OR 1.10, 95\% CI 1.08-1.12), male sex (OR 1.58, 95\% CI 1.102.29), hypertension (OR 1.50, 95\% CI 1.02-2.20), smoking (OR 2.81, 95\% CI 1.59-3.63), and lacunar stroke subtype (OR 2.45, 95\% CI 1.70-3.54) were significantly and independently associated with total SVD score, the association for smoking and lacunar stroke subtype becoming stronger in multivariable than in univariable testing. The results were similar for just those patients with a DWI-visible recent stroke lesion.

Association between total SVD score and cerebral atrophy. Both deep and superficial atrophy were significantly 


\begin{tabular}{|ll|}
\hline Table 3 & $\begin{array}{l}\text { Associations with total SVD score in } \\
\text { multivariable ordinal regression } \\
\text { analysis }\end{array}$ \\
\hline Age (per year) & OR $(95 \% \mathrm{CI})$ \\
Male sex & $1.10(1.08-1.12)^{\mathrm{a}}$ \\
\hline Diabetes mellitus & $1.58(1.10-2.29)^{\mathrm{b}}$ \\
\hline Hypertension & $0.98(0.57-1.67)$ \\
\hline Smoking & $1.50(1.02-2.20)^{\mathrm{b}}$ \\
\hline Peripheral vascular disease & $2.81(1.59-3.63)^{\mathrm{a}}$ \\
\hline Lacunar stroke & $1.64(0.75-3.61)$ \\
\hline
\end{tabular}

Abbreviations: $\mathrm{Cl}=$ confidence interval; $\mathrm{OR}=$ odds ratio; $\mathrm{SVD}=$ small-vessel disease.

Multivariable analysis with correction for all variables in the table. Because of missing variables, $n=452$ in the analysis. ${ }^{a} p<0.001$

${ }^{\mathrm{b}} \mathrm{p}<0.05$.

associated with SVD burden in unadjusted analyses (table 4). After fully adjusting for age, sex, and vascular risk factors, the association with superficial atrophy was only marginally significant, and the association of deep atrophy with SVD score became nonsignificant.

Total SVD score with alternative cutpoints of WMH. With stroke subtype as the dependent variable, total SVD score was associated with lacunar vs cortical stroke subtype (OR 1.29, 95\% CI 1.10-1.51). Varying the cutoff point in the definition of WMH improved the OR of the total SVD score for predicting lacunar stroke subtype only slightly to a maximal OR of 1.39 (95\% CI 1.16-1.37) (see table e-2).

DISCUSSION We showed that total SVD score has construct validity. We validated the initial version of the score ${ }^{12,13}$ in a much larger, diverse cohort. The score was higher in patients presenting with acute lacunar stroke compared with acute cortical stroke, and was also associated with age, male sex, smoking, and hypertension. Hypertension was considered to be the strongest vascular risk factor for SVD previously; blood pressure level was also associated with total SVD score in a smaller study. ${ }^{12}$ An important finding in the present work using the total SVD score is that smoking also was an important modifiable risk factor; the association between smoking and total SVD score was stronger than had been seen previously with individual SVD features. Smoking has been associated with both $\mathrm{WMH}^{22}$ and reduced microstructural integrity of white matter, ${ }^{23}$ less consistently with $\mathrm{CMBs}$ and lacunes, ${ }^{9,24}$ and not with PVS. ${ }^{7}$

Regarding other risk factors, diabetes is often reported as a risk factor for SVD, but it is equally common in small-vessel and large-vessel stroke ${ }^{25}$ and many studies found no association between diabetes and any of the MRI features, ${ }^{8,9,26,27}$ nor did we find an association with total SVD score. Former results regarding sex varied, some studies reporting a male, others a female preponderance for SVD features, while others did not find an association. , $9,24,27^{2}$ Although clinical classification of stroke subtype in the absence of a recent MRI infarct may introduce some diagnostic uncertainty and bias, the association between higher total SVD score and lacunar (vs cortical) stroke subtype was also present when selecting only those patients with a DWI-visible acute infarct (68\%; results not shown).

The total SVD score could be helpful for baseline stratification or as a surrogate marker for SVD in prevention and therapeutic trials if further testing confirms our results. The score provides a more complete overall view of the impact of SVD on the brain than do the individual MRI features separately. It is a simple and pragmatic visual score and allows for easy comparison and combination of data as long as standardized definitions of the individual features are adopted. ${ }^{14}$ Some may argue that there are differences in the underlying pathogenetic mechanism leading to these different SVD features. However, all of these MRI features are considered to result from disease in the small vessels, and they often co-occur. Our approach was to compile the overall brain damage resulting from SVD, not the underlying pathways. The score could be used to define patients that are at risk of (lacunar) stroke, ${ }^{28}$ e.g., for stratifying patients in secondary prevention trials. The usefulness of considering the whole spectrum of SVD abnormalities has also been shown in genetic

Table 4 Association between cerebral atrophy and total SVD score

$\begin{array}{llll} & \text { Unadjusted OR }(95 \% \mathrm{Cl}) & \text { Age- }+ \text { sex-adjusted OR (95\% Cl) } & \text { Fully adjusted } \text { OR }^{\mathrm{a}}(95 \% \mathrm{Cl}) \\ \text { Deep atrophy } & 1.81(1.52-2.16)^{\mathrm{b}} & 1.26(1.03-1.55)^{\mathrm{c}} & 1.23(0.99-1.52) \\ \text { Superficial atrophy } & 2.22(1.78-2.78)^{\mathrm{b}} & 1.41(1.09-1.83)^{\mathrm{d}} & 1.31(1.01-1.71)^{\mathrm{c}}\end{array}$

Abbreviations: $\mathrm{Cl}$ = confidence interval; OR = odds ratio; SVD = small-vessel disease.

adjusted for age, sex, stroke subtype, hypertension, diabetes mellitus, and smoking. Because of missing variables, $\mathrm{n}=542$ in this analysis.

${ }^{\mathrm{b}} \mathrm{p}<0.001$.

${ }^{c} p<0.05$.

${ }^{d} p<0.01$ 
studies. ${ }^{10}$ The score might also be useful, after further validation, in clinical practice, for example, to identify subjects at risk of cognitive decline and physical impairments, although currently this would be by extrapolation from studies on the individual features $^{2,29-31}$ and not yet formally tested for the total SVD score. Further prospective studies are required to validate these suggestions.

Further developments of the proposed "total SVD score" would be testing other weightings and different cutpoints for different SVD features, and greater granularity for features that are currently only dichotomized as yes-no, e.g., lacunes and CMBs. Different cutpoints and weightings could be tested for PVS and WMH; the present ones may not be optimal. For example, punctate deep WMH (Fazekas score 1) and a periventricular halo (Fazekas score 2) were below the cutpoint definition of WMH in the present total SVD score. We tried alternative lowered cutpoints for WMH, but these led to only slightly better performance of the SVD score-larger, more diverse datasets are required to test cutpoints more thoroughly. The cutoff for WMH in the original SVD score was chosen because those Fazekas scores were related to SVD in a small histopathology study ${ }^{12,32}$ from 2 decades ago, despite which it seems to perform reasonably well in the current study.

Cerebral atrophy is sometimes considered another MRI feature of SVD. ${ }^{14}$ While many studies report an association between atrophy and SVD, ${ }^{4,5,33}$ it is not specific to SVD, occurring in many other conditions including normal aging. We found only a weak association between superficial atrophy and total SVD score, but we may have introduced some inconsistency by combining 2 slightly different visual scoring methods. Alternatively, the association with atrophy may apply more in older populations or at different stages of SVD, or volumetric measurements of brain volume might be needed to explore this issue further. For now, there is no strong case for including atrophy in the total SVD score.

A limitation of our study is the cross-sectional design: longitudinal studies are required to explore the predictive ability of total SVD score and progression of MRI features, cognitive decline, and (recurrent) stroke risk, and to have more robust evidence that it can be used as an SVD predictor in trials, although the analysis presented here justifies its use to stratify patients according to SVD burden at randomization. A strength is the use of a recently published standard for describing imaging findings in SVD. ${ }^{14}$ Other studies using the score must ensure that the same definitions of the individual SVD features are used. The total SVD score needs further testing in independent large cohorts, with varied risk factor profiles and ethnicity, to determine its generalizability and whether different cutpoints and weighting of individual SVD features might improve the score's performance. We also suggest testing in other consequences of SVD, such as cohorts with vascular cognitive impairment and dementia, or intracerebral hemorrhage.

We found that the risk factors for SVD_-smoking, hypertension, age, and male sex-are associated with the total summed SVD score of individual MRI features. This score avoids overreliance on individual MRI features and provides a more complete view of SVD. It has potential application as a risk stratification for SVD in clinical trials or other clinical research and may (after further testing) have a useful role in clinical practice.

\section{AUTHOR CONTRIBUTIONS}

Julie Staals: study concept, analysis and interpretation of data, statistical analysis, drafting the manuscript. Stephen Makin and Fergus Doubal: acquisition of data, revising manuscript, contribution of vital assessments. Martin Dennis: supervision, data acquisition, funding, revising manuscript. Joanna Wardlaw: concept, funding, supervision and coordination, acquisition and interpretation of data, revising manuscript.

\section{STUDY FUNDING}

The contributing studies were funded by the Chief Scientist Office of the Scottish Executive (grant 217 NTU R37933) and the Wellcome Trust (grants 075611 and WT088134/Z/09/A). The imaging was performed at the Brain Research Imaging Centre Edinburgh, which is supported by the SINAPSE (Scottish Imaging Network A Platform for Scientific Excellence) collaboration and the Chief Scientist Office of the Scottish Government (http://www.bric.ed.ac.uk/).

\section{DISCLOSURE}

J. Staals was supported by MUMC Academic Fund. S. Makin was supported by the Wellcome Trust (grant WT088134/Z/09/A). F. Doubal was supported by the Wellcome Trust (grant 075611). M. Dennis reports no disclosures relevant to the manuscript. J. Wardlaw was partly funded by the Scottish Funding Council through the SINAPSE collaboration. Go to Neurology.org for full disclosures.

Received January 23, 2014. Accepted in final form May 2, 2014.

\section{REFERENCES}

1. Wardlaw J, Smith C, Dichgans M. Mechanisms of sporadic cerebral small vessel disease: insights from neuroimaging. Lancet Neurol 2013;12:483-497.

2. Pantoni L. Cerebral small vessel disease: from pathogenesis and clinical characteristics to therapeutic challenges. Lancet Neurol 2010;9:689-701.

3. Nitkunan A, Lanfranconi S, Charlton RA, Barrick TR, Markus HS. Brain atrophy and cerebral small vessel disease: a prospective follow-up study. Stroke 2011;42:133-138.

4. Appelman AP, Exalto LG, Van der Graaf Y, Biessels GJ, Mali WP, Geerlings MI. White matter lesions and brain atrophy: more than shared risk factors? A systematic review. Cerebrovasc Dis 2009;28:227-242.

5. Aribisala BS, Valdés Hernández MC, Royle NA, et al. Brain atrophy associations with white matter lesions in the ageing brain: the Lothian Birth Cohort 1936. Eur Radiol 2013;23:1084-1092.

6. Ovbiagele B, Saver JL. Cerebral white matter hyperintensities on MRI: current concepts and therapeutic implications. Cerebrovasc Dis 2006;22:83-90. 
7. Doubal FN, MacLullich AM, Ferguson KJ, Dennis MS Wardlaw JM. Enlarged perivascular spaces on MRI are a feature of cerebral small vessel disease. Stroke 2010;41: 450-454.

8. Greenberg SM, Vernooij MW, Cordonnier C, et al. Cerebral microbleeds: a guide to detection and interpretation. Lancet Neurol 2009;8:165-174.

9. Vermeer SE, Longstreth WT Jr, Koudstaal PJ. Silent brain infarcts: a systematic review. Lancet Neurol 2007;6:611-619.

10. Brenner D, Labreuche J, Pico F, et al. The reninangiotensin-aldosterone system in cerebral small vessel disease. J Neurol 2008;255:993-1000.

11. Pico F, Labreuche J, Touboul PJ, Leys D, Amarenco P. Intracranial arterial dolichoectasia and small-vessel disease in stroke patients. Ann Neurol 2005;57:472-479.

12. Klarenbeek P, van Oostenbrugge RJ, Rouhl RP, Knottnerus IL, Staals J. Ambulatory blood pressure in patients with lacunar stroke: association with total MRI burden of cerebral small vessel disease. Stroke 2013;44: 2995-2999.

13. Huijts M, Duits A, van Oostenbrugge RJ, Kroon AA, de Leeuw PW, Staals J. Accumulation of MRI markers of cerebral small vessel disease is associated with decreased cognitive function: a study in first-ever lacunar stroke and hypertensive patients. Front Aging Neurosci 2013;5:72.

14. Wardlaw JM, Smith EE, Biessels GJ, et al. Neuroimaging standards for research into small vessel disease and its contribution to ageing and neurodegeneration. Lancet Neurol 2013;12:822-838.

15. Bamford J, Sandercock P, Dennis M, Burn J, Warlow C. Classification and natural history of clinically identifiable subtypes of cerebral infarction. Lancet 1991;337:1521-1526.

16. Jackson CA, Hutchison A, Dennis MS, Wardlaw JM, Lewis SC, Sudlow CL. Differences between ischemic stroke subtypes in vascular outcomes support a distinct lacunar ischemic stroke arteriopathy: a prospective, hospital-based study. Stroke 2009;40:3679-3684.

17. Potter G, Doubal F, Jackson C, Sudlow C, Dennis M, Wardlaw J. Associations of clinical stroke misclassification ("clinical-imaging dissociation") in acute ischemic stroke. Cerebrovasc Dis 2010;29:395-402.

18. Warlow C, van Gijn J, Dennis M, et al. Is it a vascular event and where is the lesion? Identifying and interpreting the symptoms and signs of cerebrovascular disease. In: Warlow C, van Gijn J, Dennis M, et al. Stroke: Practical Management, 3rd ed. Malden, MA: Blackwell Publishing; 2008:35-130

19. Fazekas F, Chawluk JB, Alavi A, Hurtig HI, Zimmerman RA. MR signal abnormalities at $1.5 \mathrm{~T}$ in Alzheimer's dementia and normal aging. AJR Am J Roentgenol 1987;149:351-356.
20. Farrell C, Chappell F, Armitage PA, et al. Development and initial testing of normal reference MR images for the brain at ages 65-70 and 75-80 years. Eur Radiol 2009;19: 177-183.

21. Cordonnier C, Potter GM, Jackson CA, et al. Improving interrater agreement about brain microbleeds: development of the Brain Observer MicroBleed Scale (BOMBS). Stroke 2009;40:94-99.

22. Van Dijk EJ, Prins ND, Vrooman HA, Hofman A, Koudstaal PJ, Breteler MM. Progression of cerebral small vessel disease in relation to risk factors and cognitive consequences: Rotterdam Scan Study. Stroke 2008;39:27122719.

23. Gons RA, van Norden AG, de Laat KF, et al. Cigarette smoking is associated with reduced microstructural integrity of cerebral white matter. Brain 2011;134:21162124.

24. Poels M, Vernooij MW, Ikram MA, et al. Prevalence and risk factors of cerebral microbleeds: an update of the Rotterdam Scan Study. Stroke 2010;41:S103-S106.

25. Jackson CA, Hutchison A, Dennis MS, et al. Differing risk factor profiles of ischemic stroke subtypes: evidence for a distinct lacunar arteriopathy? Stroke 2010;41:624629.

26. Longstreth WT Jr, Manolio TA, Arnold A, et al. Clinical correlates of white matter findings on cranial magnetic resonance imaging of 3301 elderly people. The Cardiovascular Health Study. Stroke 1996;27:1274-1282.

27. Launer LJ. Epidemiology of white matter lesions. Top Magn Reson Imaging 2004;15:365-367.

28. Poels M, Steyerberg EW, Wieberdink RG, et al. Assessment of cerebral small vessel disease predicts individual stroke risk. J Neurol Neurosurg Psychiatry 2012;83: 1174-1179.

29. Schmidt R, Scheltens P, Erkinjuntti T, et al. White matter lesion progression: a surrogate endpoint for trials in cerebral small-vessel disease. Neurology 2004;63:139-144.

30. Patel B, Markus HS. Magnetic resonance imaging in cerebral small vessel disease and its use as a surrogate disease marker. Int J Stroke 2011;6:47-59.

31. LADIS Study Group. 2001-2011: a decade of the LADIS (Leukoaraiosis and DISability) Study: what have we learned about white matter changes and small-vessel disease? Cerebrovasc Dis 2011;32:577-588.

32. Fazekas F, Kleinert R, Offenbacher H, et al. Pathologic correlates of incidental MRI white matter signal hyperintensities. Neurology 1993;43:1683-1689.

33. Jouvent E, Viswanathan A, Chabriat H. Cerebral atrophy in cerebrovascular disorders. J Neuroimaging 2010;20: 213-218. 


\section{Neurology}

\section{Stroke subtype, vascular risk factors, and total MRI brain small-vessel disease burden Julie Staals, Stephen D.J. Makin, Fergus N. Doubal, et al.}

Neurology 2014;83;1228-1234 Published Online before print August 27, 2014

DOI 10.1212/WNL.000000000000837

\section{This information is current as of August 27, 2014}

\section{Updated Information \& Services \\ Supplementary Material}

\section{References}

Citations

Subspecialty Collections

Permissions \& Licensing

Reprints including high resolution figures, can be found at: http://n.neurology.org/content/83/14/1228.full

Supplementary material can be found at: http://n.neurology.org/content/suppl/2014/08/27/WNL.0000000000000 837.DC1

http://n.neurology.org/content/suppl/2014/09/27/WNL.0000000000000 837.DC2

This article cites 32 articles, 12 of which you can access for free at: http://n.neurology.org/content/83/14/1228.full\#ref-list-1

This article has been cited by 22 HighWire-hosted articles: http://n.neurology.org/content/83/14/1228.full\#\#otherarticles

This article, along with others on similar topics, appears in the following collection(s):

\section{Infarction}

http://n.neurology.org/cgi/collection/infarction

MRI

http://n.neurology.org/cgi/collection/mri

Information about reproducing this article in parts (figures,tables) or in its entirety can be found online at:

http://www.neurology.org/about/about_the_journal\#permissions

Information about ordering reprints can be found online:

http://n.neurology.org/subscribers/advertise

Neurology ${ }^{\circledR}$ is the official journal of the American Academy of Neurology. Published continuously since 1951, it is now a weekly with 48 issues per year. Copyright @ 2014 American Academy of Neurology. All rights reserved. Print ISSN: 0028-3878. Online ISSN: 1526-632X.

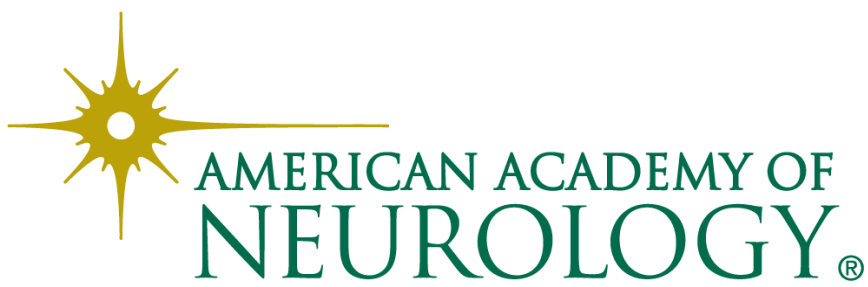

